\title{
Predicted polybrominated diphenyl ether (PBDE) and polychlorinated biphenyl (PCB) accumulation in southern resident killer whales
}

\author{
Teresa M. Mongillo ${ }^{1,3,5, *}$, Elizabeth E. Holmes ${ }^{2}$, Dawn P. Noren ${ }^{2}$, \\ Glenn R. VanBlaricom ${ }^{1,3}$, André E. Punt ${ }^{1}$, Sandra M. O'Neill ${ }^{2}$, Gina M. Ylitalo ${ }^{2}$, \\ M. Bradley Hanson ${ }^{2}$, Peter S. Ross ${ }^{4}$ \\ ${ }^{1}$ University of Washington, Seattle, Washington 98195-5020, USA \\ ${ }^{2}$ Northwest Fisheries Science Center, NOAA Fisheries, Seattle, Washington 98112, USA \\ ${ }^{3}$ Washington Cooperative Fish and Wildlife Research Unit, US Geological Survey, Seattle, Washington 98195, USA \\ ${ }^{4}$ Institute of Ocean Sciences, Fisheries and Oceans Canada, Sidney, British Columbia V8L 4B2, Canada \\ ${ }^{5}$ Present address: Northwest Regional Office, NOAA Fisheries, Seattle, Washington 98115, USA
}

\begin{abstract}
Persistent organic pollutants (POPs) are anthropogenic contaminants that bioaccumulate in upper trophic level species. Polybrominated diphenyl ethers (PBDEs) and polychlorinated biphenyls (PCBs) are POPs of particular concern because they can induce immunotoxicity, neurotoxicity, and reproductive impairment. Killer whales Orcinus orca can accumulate high concentrations of POPs because they are long-lived apex predators. Southern resident killer whales (SRKWs) are an endangered fish-eating population that consists of 3 pods (J, K, and L) with a geographic range from central California, USA, to the Queen Charlotte Islands, Canada. An individual-based modeling approach was used to predict the accumulation of sum PBDEs ( PBBDEs) and sum PCBs ( $\Sigma$ PCBs) in specific individuals in the SRKW population. Model predictions for the current concentrations corresponded closely to the concentrations measured in biopsies collected from known individuals. The predicted $\Sigma$ PBDE concentrations over the life-span of individual killer whales were consistent with a doubling time of $\sim 3$ to $4 \mathrm{yr}$, highlighting the rapid emergence of PBDEs as a priority concern in these animals. J pod individuals had the highest predicted $\Sigma$ PBDE and $\Sigma$ PCB concentrations, likely due to their increased residence time near industrial centers. Modeled historical $\mathrm{PPCB}$ concentrations did not increase substantially over time or with age in males born after 1970, whereas the $\mathrm{PBDE}$ concentrations increased over time and with age. In general, modeled future projections indicated that the average male and female had similar $\Sigma$ PBDE trends with age, time, and diet scenario. Future $\Sigma$ PCBs are predicted to slowly decline; however, SRKWs will continue to be exposed for several generations.
\end{abstract}

KEY WORDS: PCB $\cdot$ PBDE $\cdot$ Bioaccumulation $\cdot$ Killer whale $\cdot$ Model $\cdot$ Contaminants $\cdot$ Persistent organic pollutants

Resale or republication not permitted without written consent of the publisher

\section{INTRODUCTION}

Persistent organic pollutants (POPs) are lipophilic contaminants that can accumulate up food webs (Jones \& de Voogt 1999). There are several classes of POPs including the polybrominated diphenyl ethers
(PBDEs), polychlorinated biphenyls (PCBs), and other compounds (e.g. DDTs, chlordanes, hexachlorocyclohexanes [HCHs], and hexachlorobenzene [HCB]). High levels of POPs, notably PCBs, have been implicated in impaired immune systems, endocrine disruption, and increased prevalence of 
cancer, reproductive dysfunction and premature births in marine mammals (Gilmartin et al. 1976, Reijnders 1986, Aguilar \& Borrell 1994, de Swart et al. 1994, Ross et al. 1995, Schwacke et al. 2002, Fossi \& Marsili 2003, Ylitalo et al. 2005). Although the effects of PBDEs in marine mammals are unclear, PBDEs may elicit similar effects to those caused by PCBs because of their similar molecular structure and mode of action (Kodavanti 2005). Relatively high levels of PBDEs cause endocrine disruption, particularly to thyroid hormone systems, as well as adverse effects on reproductive organs in laboratory species (Hallgren et al. 2001, Legler \& Brouwer 2003, Ceccatelli et al. 2006). Exposure to lipophilic contaminants is viewed as a fundamental risk factor to the conservation of marine mammals, and may be among the factors that predispose marine mammal populations to risks of anthropogenic extinction (VanBlaricom et al. in press).

POPs enter the environment from a multitude of sources through direct release, atmospheric and ocean transport, and runoff (Iwata et al. 1993, Grant \& Ross 2002). PBDEs first appeared in the marine environment in the 1970s and continue to be used in the USA as additives in flame-retardants (Yogui \& Sericano 2009). PBDEs have a ubiquitous distribution and many marine species have shown an exponential increase in PBDE body burdens (Ikonomou et al. 2002, 2006, Rayne et al. 2003). However, increasing regulatory scrutiny and voluntary withdrawal from the marketplace indicate that PBDE releases may soon peak. In contrast, PCBs were produced and discharged in the USA beginning in the early 1920s and reached a peak in production by the 1960s and 1970s (Lefkovitz et al. 1997, Breivik et al. 2002). They had been primarily used as industrial lubricants and coolants for transformers and capacitors prior to being banned in the USA in the late 1970s after discoveries of adverse health effects in laboratory animals and suspected adverse health effects in humans.

Killer whales Orcinus orca can accumulate relatively high concentrations of PBDEs and PCBs because they are long-lived apex predators (Ross et al. 2000, Rayne et al. 2004). For example, blubber biopsy samples from known individuals indicate that the southern resident killer whale (SRKW) population is one of the most PCB-contaminated cetacean populations in the world (Ross et al. 2000, Krahn et al. 2007, 2009). SRKWs are a fish-eating population that consists of 3 matrilineally-related pods ( $\mathrm{J}, \mathrm{K}$, and L). Chinook salmon Oncorhynchus tshawytscha are the primary prey of SRKWs (Ford et al. 1998, Ford \& Ellis
2006, Hanson et al. 2010), although other fish species are also consumed (Ford et al. 1998, Hanson et al. 2010). Individual pods are likely to consume different proportions of the different salmon stocks (Krahn et al. 2007). The summer geographic range of SRKWs is comprised primarily of the semi-enclosed ('inland') marine waters of Washington, USA, and British Columbia, Canada (Bigg 1982, Osborne 1999, Hauser et al. 2007). Although there are pod-specific variations in distribution in the summer months, all 3 pods spend a large proportion of time in the Haro Strait, west of San Juan Island, Washington (Hauser et al. 2007). The winter ranges are less clear but appear to differ among pods and extend along the outer coast of British Columbia, as far north as the Queen Charlotte Islands and as far south as Monterey Bay, California (Osborne 1999, Krahn et al. 2004, 2007).

Annual surveys conducted on the SRKWs since the early 1970s (Bigg 1982) indicated a $20 \%$ population decline from 1996 to 2001 (Krahn et al. 2004). The population was listed as 'endangered' pursuant to both the Canadian Species at Risk Act (SARA) in 2003 and the US Endangered Species Act of 1973 (ESA), as amended in 2005, in response to this decline and their low numbers (less than 100 individuals). Threats to the population include motorized vessel noise (Holt et al. 2009) and disturbance (Lusseau et al. 2009, Noren et al. 2009, Williams et al. 2009), reduced prey availability (Ford et al. 2005, 2010, Ward et al. 2009), and high POP concentrations (Ross et al. 2000, Krahn et al. 2007, 2009). PBDEs and PCBs are stored in the blubber of killer whales but can become mobilized during times of nutritional stress (O'Shea 1999). Thus, the effects of contaminants may interact with and be compounded by additional stresses associated with nutritional limitation.

To date, there are data in the literature for PCB concentrations in about one third of the individuals of the SRKW population (Ross et al. 2000, Krahn et al. 2007, 2009). Even fewer data are available for PBDEs; approximately one quarter of the current population has been sampled (Krahn et al. 2007, 2009). The objectives of this study were to use a quantitative modeling approach to estimate current and historical sum PBDE ( $\mathrm{PBDE}$ ) and sum PCB $(\Sigma \mathrm{PCB})$ concentrations in individual SRKWs and to predict $\Sigma$ PBDE and $\Sigma$ PCB concentrations into the future. A similar quantitative modeling approach has been used successfully to estimate PCB accumulation for beluga whales Delphinapterus leucas in the St. Lawrence Estuary (Hickie et al. 2000), Arctic ringed seals Phoca hispida (Hickie et al. 2005), bottlenose dolphins Tursiops truncatus (Hall et al. 2006), North 
Atlantic right whales Eubalaena glacialis (Klanjscek et al. 2007), resident killer whales (Hickie et al. 2007), and harbor porpoises Phocoena phocoena (Weijs et al. 2010).

This study provides predicted historical, current, and future $\triangle \mathrm{PBDE}$ and $\mathrm{PPCB}$ concentrations in specific individuals in the SRKW population (including living and now deceased individuals) using an individual-based modeling approach based on known individual histories (e.g. birth order, reproductive history, pod membership, birth year, and sex), and contaminant concentrations in their prey. While Hickie et al. (2007) also employed an individualbased model to describe PCBs over the lifetime of generic individual killer whales, we build on this approach by providing predicted historical, current, and future $\Sigma$ PCB concentrations in known specific individuals in the SRKW population. In addition, our work provides a first attempt to model PBDEs in the SRKW population.

\section{METHODS}

\section{Individual-based model description}

The individual-based model was constructed in the $\mathrm{R}$ language (R Development Core Team 2006) and simulates the total accumulation and transfer of $\Sigma$ PBDEs and $\Sigma$ PCBs for each SRKW individual that has been identified in the annual SRKW surveys ( $\mathrm{n}=182$; survey started in the early 1970s; data courtesy of the Center for Whale Research, Friday Harbor, WA, USA). We define $\Sigma$ PCB to include the sum of congeners $17,18,28,31,33,44,49,52,66,70,74,82,87$, $95,99,101 / 90,105,110,118,128,138 / 163 / 164,149$, $151,153 / 132,156,158,170,171,177,180,183$, $187 / 159 / 182,191,194,195,199,205,206,208$, and 209. We define $\Sigma$ PBDE to include the sum of congeners 28, 47, 49, 66, 85, 99, 100, 153, 154, and 183. The supplement at www.int-res.com/articles/ suppl/m453p263_supp.pdf includes a description of the chemical analyses of killer whale blubber and their prey previously reported in Krahn et al. (2007, 2009), O'Neill et al. (2006), and in additional unpublished data from the Washington Department of Fish \& Wildlife (WDFW) and the National Marine Fisheries Service (NMFS).

The individual-based model was validated by comparing the model results to the available biopsy data ( $\mathrm{n}=14$; Krahn et al. 2007, 2009) consisting of $\Sigma$ PBDE and $\mathrm{PPCB}$ concentrations in male and calf SRKWs. The model parameters were not estimated by fitting them to the biopsy data. Rather, the predictions of the model were validated by comparing them to independently measured contaminant concentrations in biopsy samples of 14 specific individuals in the population. Details on the model structure and parameter values are provided in the supplement. Below we provide an overview of the model.

Total body growth, energetics, contaminant accumulation and transfer were modeled in individuals for each year of the individual's life. The individual age data from the annual surveys (data courtesy of the Center for Whale Research) were linked with mass-at-age estimates from Noren (2011) to estimate the mass for each individual in the population at each year during its life. The estimated mass for each individual was then used to approximate the energetic requirements for each individual at age $x$. The energetic requirement of an individual depends on its mass as well as its activity or behavior states (Kleiber 1975, Costa 2002). Noren (2011) estimated that daily energy expenditure in killer whales is between 5 and 6 times Kleiber (1975) predicted basal metabolic rate (BMR). BMR is the amount of energy required by a post-absorptive, non-reproductive adult at rest in its thermal neutral zone. Following Noren (2011), the estimates of minimum and maximum daily prey energy expenditure (i.e. 5 to 6 times Kleiber [1975] predicted BMR) were converted to minimum and maximum daily prey energetic requirements by assuming a digestive efficiency of $84.7 \%$ for killer whales (Williams et al. 2004).

Fig. 1 shows the input pathways for $\Sigma$ PBDEs and $\Sigma$ PCBs for an individual female. A male killer whale's life-cycle model is similar, but excludes the offload of contaminants via transplacental transfer and lactation. In the model, a newborn acquires a relatively small percentage (approximately 3 to $5 \%$ ) of its mother's total body burden via transplacental transfer during pregnancy. In the subsequent year, the calf nurses and accumulates an increased percentage (approximately 70 to $90 \%$ ) of the mother's total body burden. Although reproductive loss of POPs in females has been well established in marine mammals (Duinker \& Hillebrand 1979, Ridgway \& Reddy 1995, Wells et al. 2005), offload percentages are currently unknown for killer whales. However, estimated offload percentages have been measured in other delphinids (Fukushima \& Kawai 1980, Tanabe et al. 1981, Cockcroft et al. 1989, Salata et al. 1995). The model used these average ranges of offload percentage values derived from the measured offload percentages via transplacental transfer and lactation in bottlenose dolphins (Cockcroft et al. 1989, Salata et 
Fig. 1. Orcinus orca. Conceptual framework of contaminant accumulation in a female killer whale for the individual-based model. The lifecycle model has 6 stages: newborn age $x=0$, calf age $x=1$, juvenile age $x=2$ to sexual maturity, pregnant or lactating female, adult female (nonreproducing), and post-reproductive female. The arrows indicate the direction of contaminant transfer through time. The output of sum polybrominated diphenyl ethers ( 2 PBDEs) and sum polychlorinated biphenyls ( $\Sigma$ PCBs) via elimination $(E)$ is not shown, but is included for each individual at the rate $E$ times the individual's current contaminant load in the blubber

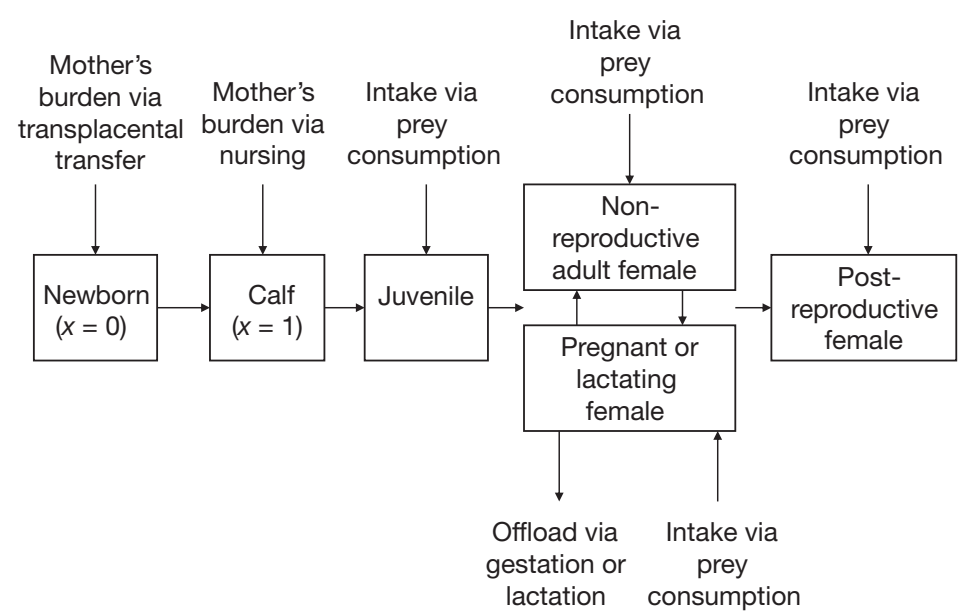

elimination rates for different congeners. Future work could include a congener-specific approach. However, such specificity is beyond the scope of this project.

A missed calf $(M C)$ factor was added to the model to compensate for any calves that were missed during the annual surveys (surveys performed by the Center for Whale Research). Calves can be missed if they are born during the winter and die prior to the annual summer surveys. The $M C$ factor is important not only for missed calves that may have been born and died before the annual summer surveys, but also for calves missed prior to the initial surveys in the early 1970s. It is probable that a current adult female that was sexually mature prior to the initial surveys and has not been observed with offspring, gave birth several times and lost the calves prior to the initial surveys. In general, female killer whales mature sexually and give birth to their first calf between the ages of 12 and $17 \mathrm{yr}$, and reproductive senescence usually occurs by age 40 (Olesiuk et al. 2005). The majority of females with known histories have calving intervals of 3 to $7 \mathrm{yr}$ (Olesiuk et al. 2005). If a reproductive female was not observed with a calf within the average interval of $5 \mathrm{yr}$ since her previous calf, it was assumed that a calf was missed and a 'missed calf' is generated. Four percent of the mother's total body burden is subsequently offloaded via 'transplacental transfer' and $80 \%$ of the mother's total body burden is offloaded via 'lactation' to the 'missed calf'.

Parameter values were selected at random from specified plausible ranges to capture inherent uncertainty. The parameters that were varied in different simulations included the percentage offloaded via gestation and lactation and the $\Sigma$ PBDE and $\Sigma \mathrm{PCB}$ elimination rates. Within a simulation, some parapotential limitations of accuracy in assuming similar 
meters varied yearly and other parameters varied among individuals. The parameters that varied yearly included the prey's caloric content and contaminant concentration. Parameters that varied among individuals included the total body mass, blubber mass, lipid blubber weight, energetic requirements, annual biomass of fish consumed, and contaminant concentration acquired from prey consumption. The supplement at www.int-res.com/articles/suppl/m453 p263_supp.pdf includes a description of the management of each of our model parameters in detail.

\section{Historical contaminant profile model}

We assume for our simulations that all 3 pods in the SRKW population consumed solely Chinook salmon. Although this is a simplified diet, research on SRKWs indicates that Chinook salmon are the predominant prey species (Ford et al. 1998, Ford \& Ellis 2006, Hanson et al. 2010).

A recent study examining POP patterns in Chinook salmon from the inland waters (e.g. Puget Sound, the Strait of Juan de Fuca, and the waters adjacent to the San Juan archipelago), and the continental shelf (outer coast) waters from Washington to California, indicate that contaminant concentrations vary by geographic location (O'Neill et al. 2006, WDFW \& NMFS unpubl. data). Adult salmon that feed in the Puget Sound are at a greater risk of exposure to contaminants than those that feed in the Strait of Georgia or the outer coast because of proximity to urban areas, the increased residence time of water that can prolong exposure to POPs, and the highly contaminated pelagic food web (O'Neill \& West 2009).

Resident Chinook salmon spend more time within the Puget Sound waters than conspecifics, which migrate out of the Puget Sound and spend more time feeding off the outer coast. Thus, resident Chinook salmon likely experience increased exposure to contaminants as compared to outer coast conspecifics. For example, O'Neill et al. (2006) measured higher PBDEs in resident Chinook salmon (approximately $40 \mu \mathrm{g} \mathrm{kg}^{-1}$ wet weight [ww]) than in Chinook salmon that migrate out of the Puget Sound (approximately $20 \mu \mathrm{g} \mathrm{kg}^{-1} \mathrm{ww}$ ). Historical time series are not available for PBDE concentrations in Chinook salmon, however, trends in PBDE levels were tracked in mountain whitefish Prosopium williamsoni and largescale sucker Catostomus macrocheilus from the Columbia River system from 1992 to 2000 (Rayne et al. 2003) and in Dungeness crab Cancer magister in British Columbian waters from 1994 to 2000 (Ikono- mou et al. 2006). Results from these studies indicate that PBDE concentration levels have increased exponentially. These local increases in PBDE concentrations match general trends in levels of PBDEs on a global scale. PBDE doubling times reported in other marine mammal studies range from 3 to $8.6 \mathrm{yr}$ (Ikonomou et al. 2002, Hites 2004, Lebeuf et al. 2004).

In the model, the PBDE accumulation from the prey was zero in 1970 and increased exponentially with a doubling time ranging from 3.2 to $4.0 \mathrm{yr}$ (with variations among the pods and from year to year). These doubling times were chosen because they are consistent with what is seen in other local marine species (Ikonomou et al. 2002, 2006, Rayne et al. 2003) and were also found to be a reasonable assumption during model validation. In more recent years, there is some indication that PBDE concentrations may be leveling off. For example, PBDE levels from 1994 to present have not shown any substantial increase in Puget Sound herring, a key prey for Chinook salmon (West \& O'Neill 2007). However, since this evidence is limited, we did not include a leveling off of PBDE prey concentrations in the model.

The average PCB concentration measured in the early 2000s was $35 \mu \mathrm{g} \mathrm{kg}{ }^{-1}$ ww in inland Chinook salmon, and $17 \mu \mathrm{g} \mathrm{kg}^{-1} \mathrm{ww}$ in outer coast Chinook salmon (WDFW \& NMFS unpubl. data). Similar contaminant concentrations were documented in Chinook salmon sampled during the mid-1990s and early 2000s (O'Neill \& West 2009).

In our model, $\Sigma$ PCB concentrations in inland Chinook salmon were estimated as the combined average values (WDFW \& NMFS unpubl. data) of Chinook salmon from the Fraser $(\mathrm{n}=13)$, Duwamish $(\mathrm{n}=$ $25)$, Nooksack ( $\mathrm{n}=14)$, Nisqually $(\mathrm{n}=30)$, and Deschutes River ( $\mathrm{n}=14$ ) watersheds. $\Sigma$ PCB concentrations in outer coast Chinook salmon were estimated as the average values (WDFW \& NMFS unpubl. data) of Chinook salmon from the Sacramento ( $\mathrm{n}=29$ ), Columbia (fall $\mathrm{n}=20$, and spring $\mathrm{n}=20$ runs), and Skeena River ( $\mathrm{n}=30$ ) watersheds. Although there are differences in size, caloric content, and POP levels in Chinook salmon between the Fraser River and Puget Sound population complexes, there is insufficient data to accurately represent the contaminant levels in specific Chinook salmon stocks. Therefore, a simpler approach that assumes a wide range of contaminant levels in SRKW diet was used.

Two dietary scenarios were run to simulate current $\mathrm{PCB}$ accumulation in SRKWs. In the 'uniform' scenario, J pod exclusively consumed the more contaminated Chinook salmon from the inland marine 
waters of British Columbia and Washington State, whereas $\mathrm{K}$ and L pods exclusively consumed the less contaminated Chinook salmon from along the outer coast from Vancouver Island to California. The 'mixed' scenario assumed J pod consumed Chinook salmon from the inland waters two thirds of the time and consumed outer coast Chinook salmon one third of the time to correspond with their seasonal distribution (Bigg 1982, Osborne 1999, Krahn et al. 2004, Hauser et al. 2007). Conversely, K and L pods consumed Chinook salmon from the inland waters one third of the time and consumed Chinook salmon from the outer coast two thirds of the time, also reflecting their seasonal distribution (Bigg 1982, Osborne 1999, Krahn et al. 2004, Hauser et al. 2007).

Although there is no historical time series of data for PCB concentrations in Chinook salmon, PCB levels in sediments in the inland marine waters included in our study have been estimated since the early 1900s (Lefkovitz et al. 1997), in harbor seals Phoca vitulina since the mid-1980s (Calambokidis et al. 1999), and in coho salmon Oncorhynchus kisutch since the mid-1970s (West \& O'Neill 2007). Lefkovitz et al. (1997) reported a steady increase in PCB concentration in sediments of inland waters beginning in 1930 with levels peaking in the early 1960s. Levels in the 1960s were approximately 4 times higher than the current PCB sediment concentrations. Inland harbor seal PCB concentrations decreased dramatically from 1970 to the mid-1980s, and were relatively constant from the mid-1980s to the late 1990s (Calambokidis et al. 1999). Similarly, PCB concentrations in coho salmon from Puget Sound declined dramatically from the mid-1970s to the mid-1980s but have not declined substantially since the early 1990s.

The sediment and harbor seal PCB historical time series were used as proxies for the historical PCB contaminant loads in inland Chinook salmon. Current proxy levels were set to the lower and upper $95 \%$ confidence intervals for current average Chinook salmon PCB concentration levels $(29$ and $41 \mu \mathrm{g}$ $\mathrm{kg}^{-1} \mathrm{ww}$ lower and upper CI, respectively, for inland Chinook salmon; and 14 and $19 \mu \mathrm{g} \mathrm{kg}^{-1}$ ww lower and upper CI, respectively, for outer coast Chinook salmon) by multiplying the proxy levels by scaling factors. To estimate the PCB trend in inland Chinook salmon, a time series for the proxies for the period 1931 to 2007 was developed, using a piecewise linear function divided into 3 time periods. In the USA and globally, numerous studies have shown that PCB concentrations in fish declined rapidly in the 1970s, but the rate of decline has slowed or leveled off since the mid-1980s (Matta et al. 1986, Stow et al. 1994,
Bignert et al.1998, Lamon et al. 1999, Hickey et al. 2006). For simplicity, outer coast Chinook salmon were assumed to have PCB levels that increased linearly from 1930 (no PCBs) to current levels. Although this is a simplified general linear trend in outer coast contamination, sensitivity analyses indicated that this trend did not significantly affect the model results, and was found to be a reasonable assumption during model validation.

Sensitivity analyses were conducted to determine how the results of the models were influenced by uncertainty in the values for the parameters. The parameter values were sequentially extended by $\pm 10 \%$. In addition, the initial year of $\Sigma$ PBDE accumulation was altered by $\pm 10 \mathrm{yr}$. The output of each sensitivity test was compared to the output values for the original parameter values and the percent change was calculated for each original output value.

\section{Projection model description for future contaminant levels}

The second objective of this study was to use the individual-based accumulation model to project future contaminant levels (post 2007) in the SRKWs. The projection model for future contaminant levels used a similar conceptual framework as the individual-based model. It was 'started' in 2008 with the estimated individual $\Sigma$ PBDE and $\Sigma$ PCB contaminant loads for killer whales with known mothers. For each individual in the population for each year they were projected to be alive, the model generated the developmental growth and energetic requirements for the specific age and sex classes using the average parameter values. Survival was set to equal 1.0 for all age and sex classes in order to track an individual's potential accumulation and compare contaminant levels among individuals in the same life history stage. Results include $\Sigma \mathrm{PBDE}$ and $\mathrm{PPCB}$ concentrations in the average simulated individual (i.e. the new calves produced by the projection model) for each projected year through 2050.

Several factors can influence the degradation rates of PBDEs and PCBs, ranging from microbial communities in the sediments to environmental temperature patterns (Sinkkonen \& Paasivirta 2000, Gouin \& Harner 2003). PCB congeners have a range of estimated environmental half-lives from a few years to over $100 \mathrm{yr}$ (Sinkkonen \& Paasivirta 2000, Jönsson et al. 2003). Given the multifactorial influences on degradation rates (Sinkkonen \& Paasivirta 2000), and based on model validation and sensitivity analyses 
results, 3 scenarios were run for future $\Sigma$ PBDE and $\Sigma$ PCB accumulation. The 3 scenarios simulated for $\Sigma$ PBDE accumulation assumed that concentration levels in the prey will increase at an exponential rate. The first scenario ('3.2') assumed a doubling time of $3.2 \mathrm{yr}$, the second scenario ('3.6') assumed a doubling time of $3.6 \mathrm{yr}$, and the third scenario ('4.0') set the doubling time at $4.0 \mathrm{yr}$. The first scenario (' $\mathrm{C}$ ') for $\Sigma$ PCB accumulation assumed that $\Sigma$ PCB concentration in the prey will remain constant at current levels. The second scenario (' $\mathrm{H}^{\prime}$ ) assumed $\Sigma \mathrm{PCB}$ levels in the prey will be reduced in half by 2050. The third scenario ('Z') assumed that prey $\Sigma$ PCB concentrations will be undetectable by 2050 .

\section{RESULTS}

\section{Individual-based model validation}

Modeled predictions for current concentrations of $\Sigma$ PBDE and $\Sigma$ PCB in SRKW corresponded to concentrations measured in biopsies of known individuals. The predicted $\Sigma$ PBDE concentrations for J, K, and L pod individuals were consistent with an exponential increase in 5 PBDE concentration over the lifetime of these individuals. Doubling times were between 3.2 and $4.0 \mathrm{yr}$ and produced results closest to the data $\left(\mathrm{R}^{2}=0.86\right.$; Fig. 2). Overall, $\Sigma$ PBDE concentrations in $\mathrm{J}$ and $\mathrm{K}$ pods were best predicted using a shorter con-

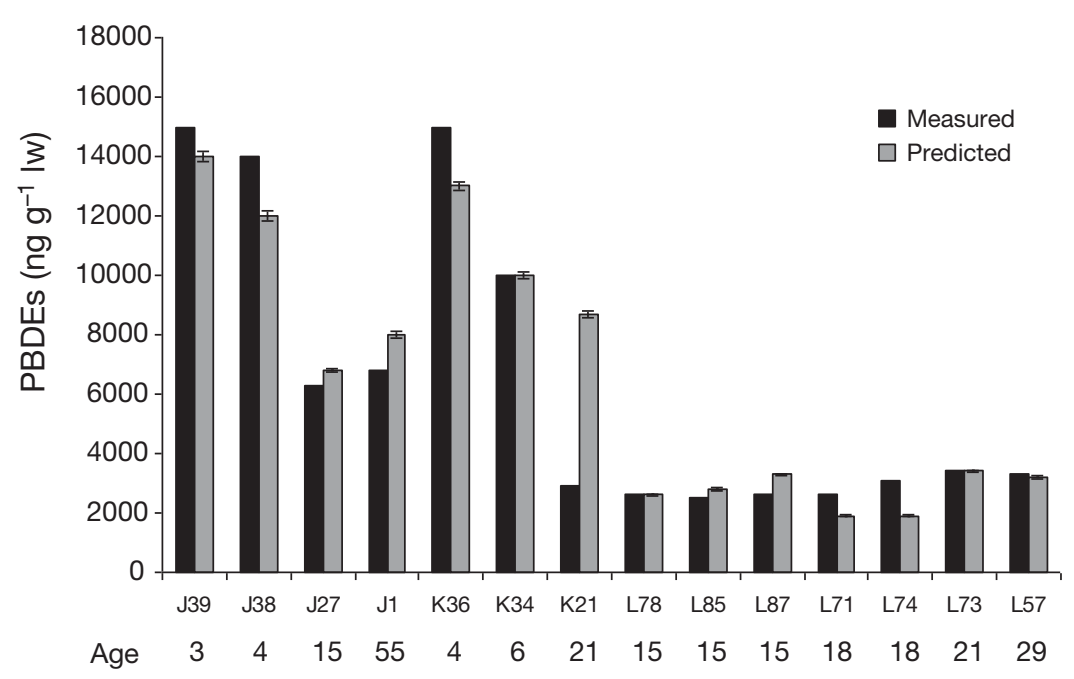

Fig. 2. Orcinus orca. Measured concentrations of $\Sigma$ PBDE in blubber biopsy samples of 14 individual southern resident killer whales (SRKWs) from Krahn et al. $(2007,2009)$ compared to current predicted $\Sigma$ PBDE concentrations (+SE) from the individual-based model $\left(R^{2}=0.86\right)$. Ages of the whales are shown below their ID number. J and $\mathrm{K}$ pod individuals had a $\Sigma$ PBDE doubling time range of 3.2 to $3.5 \mathrm{yr}$, and $\mathrm{L}$ pod individuals had a doubling time range of 3.7 to 4.0 yr. $\Sigma$ PBDE blubber levels are reported as $\mathrm{ng} \mathrm{g}^{-1}$ lipid weight (lw) centration doubling time range of 3.2 to $3.5 \mathrm{yr}$, whereas the $\Sigma$ PBDE concentrations for L pod were best predicted when the doubling time was between 3.7 to $4.0 \mathrm{yr}$. However, the predicted $\Sigma$ PBDE value in one of the $3 \mathrm{~K}$ pod individuals (K21, an adult male), was overestimated when the concentration doubling times were between 3.2 and 3.5 yr. K21 was subsequently better predicted with the slower predicted doubling time (3.7 to $4.0 \mathrm{yr}$ ) of $\mathrm{L}$ pod individuals. Thus, it may be that $\mathrm{K}$ pod individuals have slower $\Sigma$ PBDE accumulation rates, similar to L pod individuals, because of their similar geospatial distribution (Osborne 1999, Krahn et al. 2004, 2007). In contrast, the remaining $2 \mathrm{~K}$ pod juveniles, K34 and K36, are under-predicted when the slower doubling time $(3.7$ to $4.0 \mathrm{yr}$ ) is used, possibly indicating a discrepancy in the maternal offload they received. Unfortunately, the small sample size of $\mathrm{K}$ pod individuals precludes a more accurate validation of $\Sigma$ PBDE prey-concentration doubling times.

In general, the 'mixed' diet scenario, in which SRKWs eat Chinook salmon from both inland and outer coast waters, best predicted $\Sigma$ PCB concentration levels in the majority of individuals $\left(\mathrm{R}^{2}=0.5\right.$; Fig. 3). However, $\Sigma$ PCBs were not as accurately predicted as $\Sigma$ PBDEs. The 'uniform' diet scenario, in which J pod exclusively eats Chinook salmon from inland waters and $\mathrm{K}$ and $\mathrm{L}$ pods exclusively eat Chinook salmon from the outer coast, under-estimated $\Sigma$ PCB levels in individuals from $\mathrm{J}, \mathrm{K}$, and L pods, with the exception of 2 young juveniles from J pod. J39, a young male calf, had $\Sigma$ PCB levels that were over-predicted in both diet scenarios (Fig. 3). Relatively small changes $(<5000 \mathrm{ng}$ $\mathrm{g}^{-1} \mathrm{lw}$ ) in the mother's total body burden could result in the discrepancy seen between the predicted and measured $\sum$ PCB levels in this calf.

\section{Effects of age, accumulation year, and birth order}

The effects of age and year on contaminant levels in male killer whales are demonstrated by the simulated historical contaminant profiles of 5 males with different birth years (Fig. 4). In the simulated profiles, PBDE concentrations among male killer whale calves increased substantially over time, from the 1970 s to 


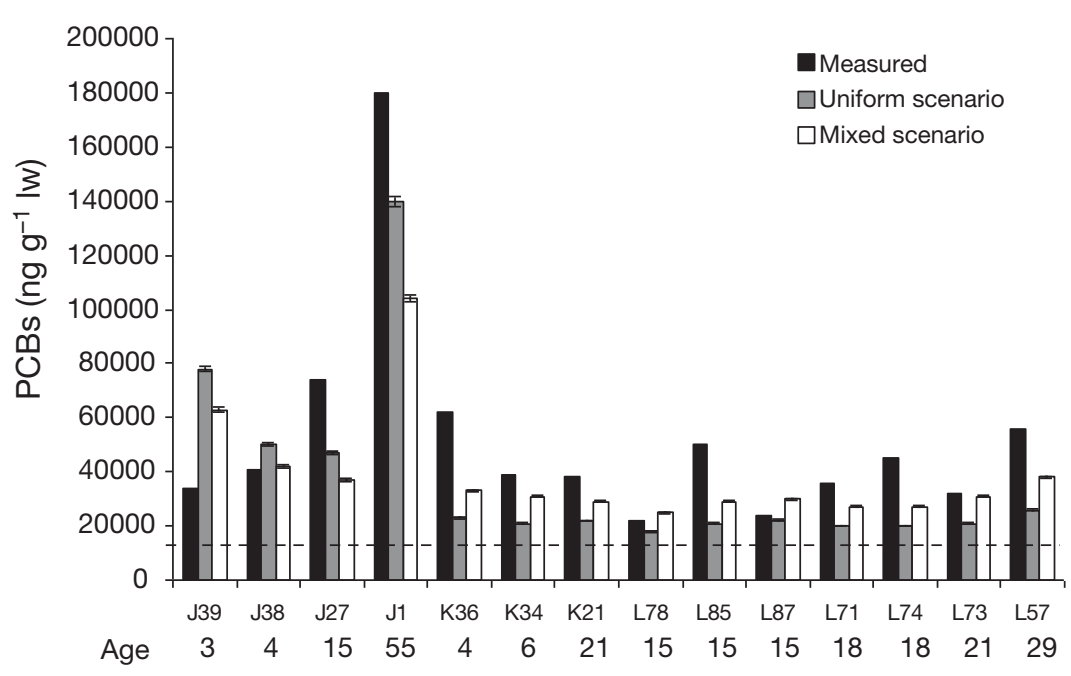

Fig. 3. Orcinus orca. Measured concentrations of $\Sigma$ PCB in blubber biopsy samples of 14 individual SRKWs from Krahn et al. $(2007,2009)$ compared to current predicted $\Sigma \mathrm{PCB}$ concentrations $(+\mathrm{SE})$ from the individual-based model $\left(\mathrm{R}^{2}=\right.$ 0.5). Ages of the whales are shown below their ID number. $\Sigma$ PCB blubber levels are reported as $\mathrm{ng} \mathrm{g}^{-1} \mathrm{lw}$. The horizontal dashed line indicates a threshold for PCB health- related effects in marine mammals (Kannan et al. 2000)

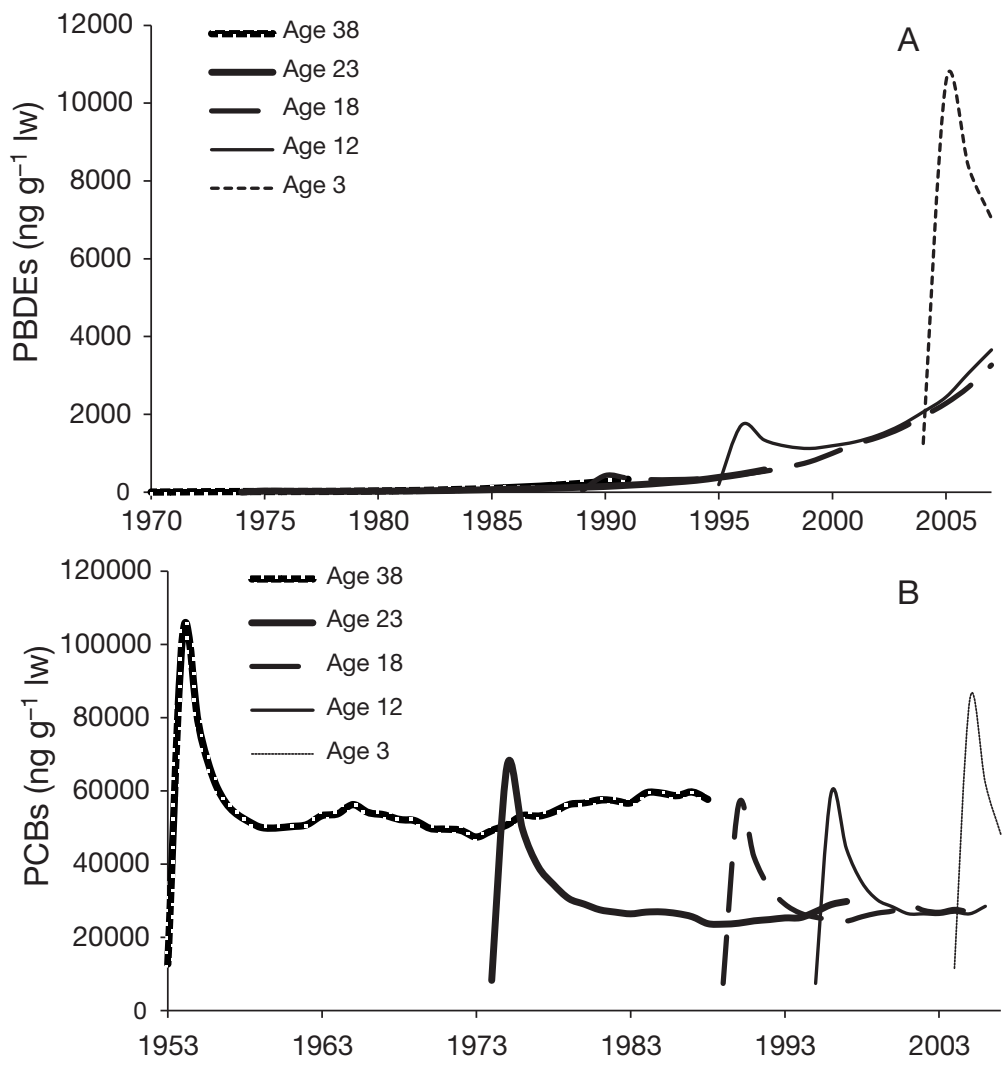

Fig. 4. Orcinus orca. Reconstructed historical (A) $\Sigma$ PBDE profiles (1970 to 2007) and (B) $\Sigma$ PCB profiles (1953 to 2007) for 5 males. The steep rise for each individual represents the accumulation of contaminants from the mother and the drop in concentration in young juveniles represents the dilution caused by growth. The ages indicate the current age (year $=2007$ ) of the individual, or the age of the individual when it died
2007, and continued to increase with age within males after the period of growth dilution (Fig. 4A). $\Sigma$ PBDE levels in the 12 and $18 \mathrm{yr}$ olds were approximately double that predicted in the 23 and 38 yr olds from the previous decade (Fig. 4A). In the simulated profiles, $\Sigma \mathrm{PCB}$ concentrations declined through time from the 1950s to the 1990s. However, there was no evidence of a decline from the 1990s to the present (Fig. 4B). The male profiles indicated that individuals born after the 1970 s did not have $\Sigma$ PCB concentrations that increased with age following the period of growth dilution and prior to physical maturation (i.e. approximately between the ages of 5 and $20 \mathrm{yr}$; Fig. 4B). In contrast, the male killer whale born in the 1950s had a positive relationship between age and $\Sigma$ PCB concentration (Fig. 4B).

The effects of birth order are apparent as demonstrated by the average simulated contaminant profiles of a mother and her offspring from $\mathrm{J}$ pod (Fig. 5). In the simulations, individuals had increasing $\Sigma$ PBDE concentrations with increasing birth order, or more specifically, had increasing $\Sigma \mathrm{PBDE}$ concentrations through time, although there was no difference in current IPBDE concentrations between the 2nd and 3rd born individuals (Fig. 5A). In contrast, these same individuals had decreasing $\mathrm{PPCB}$ concentrations with increasing birth orders prior to the 3rd offspring while subsequent calves had relatively similar $\Sigma$ PCB levels (Fig. 5B).

\section{Sensitivity analyses of results from the individual-based model validation}

The predicted $\Sigma$ PBDE and $\Sigma$ PCB concentrations changed by less than $10 \%$ when most of the parameter values were changed by $\pm 10 \%$. $\Sigma$ PBDE predictions were sensitive to the start year (causing the $\Sigma$ PBDE concentrations to change by more than $100 \%$ in all individuals across models with dif- 


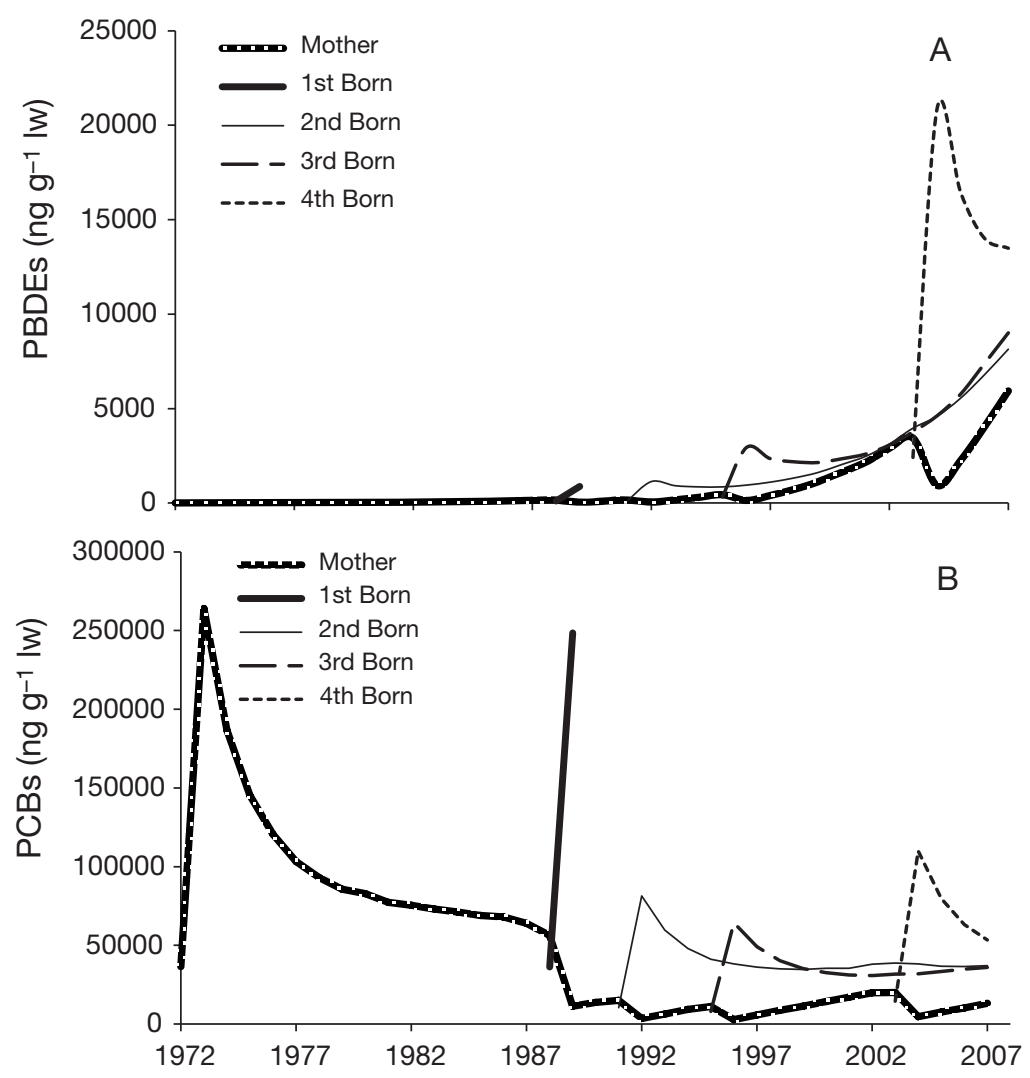

Fig. 5. Orcinus orca. Predicted historical (A) $\Sigma$ PBDE profiles and (B) $\Sigma$ PCB profiles for a mother and her offspring. For the mother, the decrease in concentration represents a birth. The first-born offspring died after lactation by the end of the first year. The drops in concentrations shortly after birth represent a dilution caused by growth

ferent start years) and the doubling time (causing the $\Sigma$ PBDE concentrations to differ between $38 \%$ and $71 \%$ across different models). $\mathrm{PPCB}$ concentrations were changed by a maximum difference of $31 \%$ when the $M C$ factor was removed. In general, the sensitivity analyses indicate that the predicted $\Sigma$ PBDE accumulation is most sensitive to the rate of accumulation (i.e. the start year and the doubling time), and the predicted $\Sigma$ PCB accumulation is most sensitive to the mother's total burden prior to offloading as reflected by the removal of the $M C$ factor. In the future contaminant projection model, individuals with unknown mothers or unknown birth order were therefore excluded and a range of plausible $\Sigma$ PBDE accumulation rates was simulated.

\section{Future contaminant projection model}

The projection model results include predicted contaminant concentrations for the average individuals (i.e. simulated new individuals) for the 3 $\Sigma \mathrm{PBDE}$ diet scenarios ('3.2', '3.4', '4.0') and the 3 $\Sigma$ PCB diet scenarios (' $\mathrm{C}$ ', ' $\mathrm{H}$ ', ' $\mathrm{Z}$ '). Contaminant concentrations in these average individuals were calculated from the average $\Sigma \mathrm{PBDE}$ and $\Sigma \mathrm{PCB}$ concentrations for each age and sex class in each year in the simulated individuals from 2008 to 2050.

In general, the average male and female had similar 5 PBDE trends with age, time, and diet scenario (Fig. 6). $\Sigma$ PBDE concentration levels increased through time and with decreasing doubling times (Fig. 6). Adult and sub-adult males appeared to have similar $\Sigma \mathrm{PBDE}$ concentrations in similar scenarios (Fig. 6A). In contrast, the average reproductive female had distinctively lower $\Sigma$ PBDE concentration levels than the average post-reproductive female by 2015 (Fig. 6B).

In general, projected $\Sigma \mathrm{PCB}$ concentrations were highest in calves, followed by adult males, post-reproductive females, sub-adult males, and lastly reproductive females (Fig. 7). When the $\Sigma$ PCB concentration in the prey was reduced, the average male experienced an increase in $\Sigma \mathrm{PCB}$ concentration with age following the growth dilution, but a decrease in $\Sigma \mathrm{PCB}$ concentration through time among similar age-classes (Fig. 7A). The average female experienced a reduction in $\triangle \mathrm{PCB}$ concentration due to a growth dilution and the ability to offload during reproductive years, followed by an increase in $\Sigma \mathrm{PCB}$ concentration post-reproduction (Fig. 7B). Within similar adult age-classes, there appeared to be less distinction in $\Sigma$ PCB concentrations in 2020 among scenarios (Fig. 7). Differences in $\Sigma$ PCB concentrations only began to appear substantial among scenarios after 2020, revealing a lag time of change of at least 12 yr (from 2008 to 2020).

\section{DISCUSSION}

Several challenges prevent an accurate assessment of the total annual $\Sigma$ PBDE and $\Sigma$ PCB exposure to the SRKWs. Following Hickie et al. (2007) and Cullon et al. (2009), POP levels in Chinook salmon were used as a proxy for POP exposure. We used an individualbased modeling approach to accurately predict the current accumulation of $\Sigma$ PBDEs and $\Sigma$ PCBs in spe- 


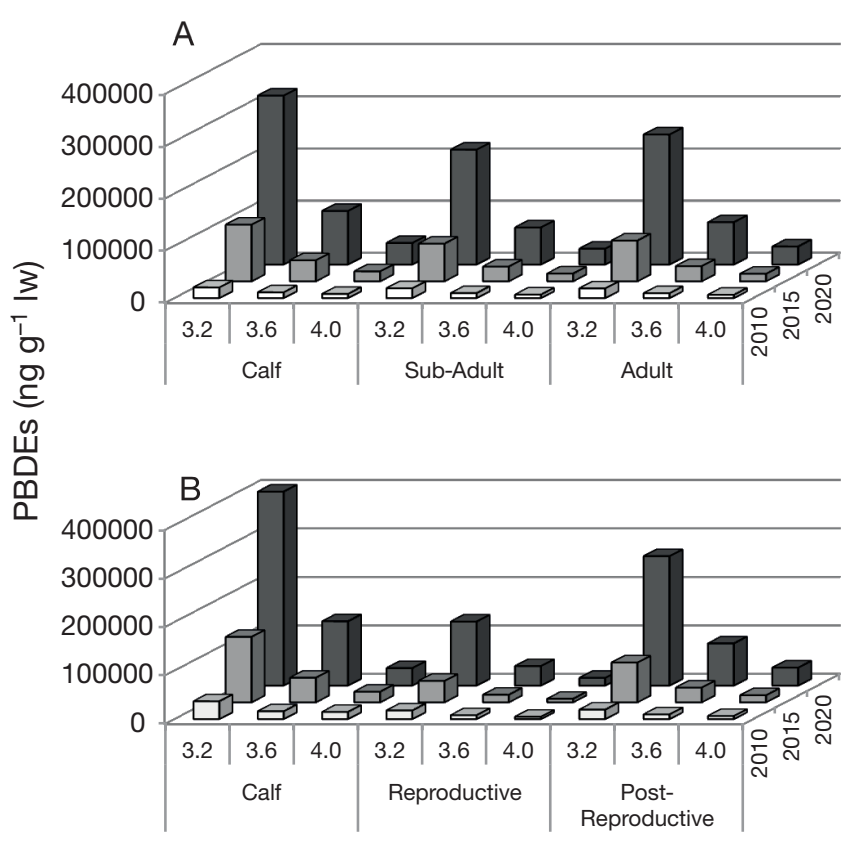

Fig. 6. Orcinus orca. Predicted 2010, 2015, and 2020 SPBDE concentrations for average simulated (A) male and (B) female SRKWs using 3 diet scenarios, assuming an exponential increase with doubling times 3.2, 3.6, and $4.0 \mathrm{yr}$. Age classes indicated on the $x$-axis are $2-4,17$, and $33-38$ yr for calf, sub-adult and adult males, respectively; and 3-5, 17, and 49-51 yr for calf, reproductive and post-reproductive females, respectively. Age classes differ between sexes because they were chosen to include at least one individual in each class in all 3 scenarios

cific individuals in the SRKW population from a simplified diet of $100 \%$ Chinook salmon. Based on the model results, SRKWs appear to be accumulating $\Sigma$ PBDEs at an exponential rate. While data for mountain whitefish from the Columbia River indicated PBDE doubling times of under 2 yr (Rayne et al. 2003), the results of this study suggest that the observed data are most consistent with doubling times for killer whales between 3.2 and $4.0 \mathrm{yr}$, assuming individuals started accumulating PPBDEs in the 1970s. Individuals in J pod appear to be accumulating $\Sigma$ PBDEs slightly faster than individuals in L pod (i.e. a doubling time range of 3.2 to $3.5 \mathrm{yr}$ for $\mathrm{J}$ pod versus 3.7 to $4.0 \mathrm{yr}$ for $\mathrm{K}$ and $\mathrm{L}$ pods). In most cases, $\mathrm{J}$ pod individuals also had higher predicted $\Sigma$ PBDE and $\Sigma \mathrm{PCB}$ concentrations than $\mathrm{K}$ or $\mathrm{L}$ pod individuals because they were represented as consuming relatively higher proportions of the inland Chinook salmon that have relatively higher levels of these compounds than the outer coast Chinook salmon (O'Neill et al. 2006, O'Neill \& West 2009).

Our results indicate that $\Sigma$ PCBs were more difficult to predict than $\Sigma$ PBDEs, possibly due to the long his-

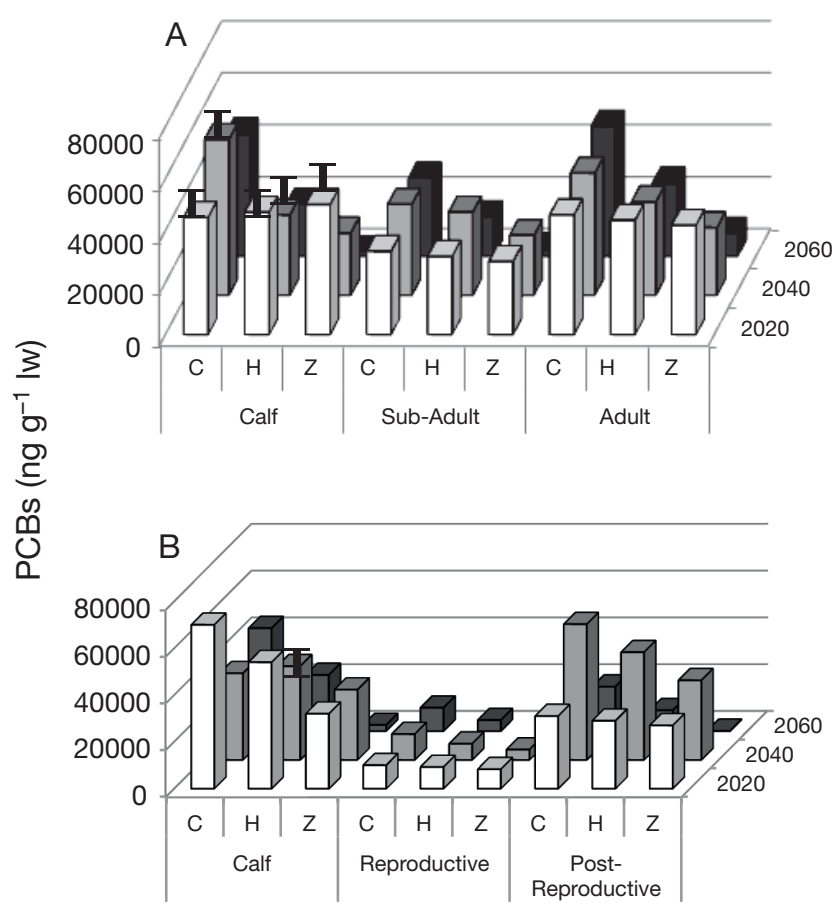

Fig. 7. Orcinus orca. Predicted 2010, 2015, and 2020 EPCB concentrations for average simulated (A) male and (B) female SRKWs using 3 diet scenarios: a constant diet (C), a diet where the PCB concentration in the prey is reduced by $50 \%$ by $2050(\mathrm{H})$, and a diet where the PCB concentration in the prey is zero by $2050(\mathrm{Z})$. Age classes indicated on the $x$ axis are 2-4, 17, and 33-38 yr for calf, sub-adult and adult males, respectively; and 1, 29, and 49 yr for calf, reproductive and post-reproductive females, respectively. Age classes differ between sexes because they were chosen to include at least one individual in each class in all 3 scenarios. Standard error bars are shown where SE > $5000 \mathrm{ng} \mathrm{g}^{-1}$ lw in the blubber

tory of exposure to PCBs in the aquatic environment compared to PBDEs. However, the discrepancies between the current predicted and measured concentrations could also be due to a dietary shift from predominantly Chinook salmon to a more diverse diet in recent years. Recent results of stable isotope values of nitrogen indicate a possible shift in the diet of $\mathrm{L}$ pod individuals over the last decade (Krahn et al. 2009). Increasing the sample size so that all life history stages are represented for each pod would provide for a more thorough examination of the distinction in diet among the pods, and the consequences thereof for patterns of accumulation and loss of $\Sigma$ PBDEs and $\Sigma$ PCBs.

Some of the observed discrepancy between the current predicted and measured contaminant concentrations in the SRKW calves may be due to differences in transfer rates of the different PCB and PBDE congeners. Currently, there is limited information on 
the transfer of PBDEs and PCBs from cetacean females to their offspring during gestation and lactation. Transfer rates of POPs to offspring can vary widely, and can depend on molecular weight and structure. Borrell \& Aguilar (2005) demonstrated that, in the common dolphin Delphinus delphis, the transfer efficiency of PCBs and DDTs from mother to calf declined proportionately with the number of chlorine congeners. Similarly, in some cetaceans the larger and more brominated PBDE congeners are less transferable from females to their offspring during gestation and lactation (Kajiwara et al. 2008). Therefore, it is likely that the congener composition in the calves consists largely of the lower brominated/ chlorinated congeners. Our model was a first attempt at predicting transfer in specific individuals and for simplicity used a generic transfer rate of 3 to $5 \%$ for gestation and 70 to $90 \%$ for lactation. Future work should include a refinement of congener-specific transfer rates.

Excluding the rate and initial year of accumulation of $\Sigma$ PBDEs, and the $M C$ factor, uncertainty in the model parameters appeared to have little effect on model results. Removing the $M C$ factor from the model causes the predicted $\Sigma$ PBDE and $\Sigma$ PCB levels in some individuals to be higher than the measured levels. One suggested explanation for the overestimation is that a reproductive female that has not been observed with a calf within the predicted $5 \mathrm{yr}$ calving interval (Olesiuk et al. 2005) has probably given birth, but the calf subsequently died before being observed in the summer annual surveys. Accurate data for calf mortalities and calving intervals are important because it has been suggested in bottlenose dolphins that high levels of PCBs from the mother can affect calf mortality (Schwacke et al. 2002, Hall et al. 2006).

The projection results suggest that future $\Sigma$ PBDE levels will surpass current $\triangle \mathrm{PCB}$ levels in the near future (approximately 5 to $20 \mathrm{yr}$ ), emphasizing the need for an accurate estimate of current and future PBDE doubling times in the killer whales. It should be noted that the production of certain PBDE technical mixtures (e.g. penta-BDE and octa-BDE) is being discontinued by the sole manufacturer and that doubling times may change as a result of the phase-out of these compounds as new products will be used in their place. In addition, the chemistry of PBDEs and PCBs differs as carbon-bromine bonds are more readily broken than carbon-chlorine bonds. Based on this difference, the environmental fate and metabolism of PBDEs compared to PCBs is expected to differ as well.
Several biological factors are responsible for the variation of persistent pollutant concentrations in marine mammals. The primary factors include diet, spatial and temporal habitat use, body size and growth, body composition, nutritive condition, disease, age, sex, birth order, and differences in biotransformation of contaminants (Aguilar et al. 1999, Ross et al. 2000, Ylitalo et al. 2001, Borgå et al. 2004). We predicted that future $\Sigma$ PBDE concentrations among male killer whales will increase with age and over time, reflecting continued use and/or release of PBDEs in North America. Prior to the ban of PCBs in the 1970s, concentrations in male killer whales were presumed to have increased with age (Hickie et al. 2007). Based on the historical profiles in this study, however, a few sub-adult male killer whales born after the 1970s were predicted to have experienced no increase of $\Sigma$ PCB concentrations with age. Historical concentrations of $\Sigma$ PBDEs and $\Sigma$ PCBs in female killer whales were predicted to remain relatively low following growth dilution and increase in the postreproductive years, consistent with biopsy-based measurements in free-ranging killer whales (e.g. Ross et al. 2000). While our predicted $\Sigma$ PCB concentrations in killer whales decreased with increasing birth order, predicted $\Sigma$ PBDE concentrations increased with increasing birth order. This likely reflects declining environmental (prey) concentrations of PCBs, and continued use of PBDEs.

SRKW calves had the highest predicted $\Sigma$ PBDE and $\mathrm{PCB}$ concentrations compared to any other age class in most scenarios, likely because of their small size and the relatively high contaminant loads received from their mothers. In addition, calves are potentially at a higher risk of health effects from contaminant exposure than adults because high contaminant levels accumulate during a period of rapid biological development. Eriksson et al. (2006) demonstrated that when neonatal mice were exposed to a PBDE and a PCB congener during a critical period of brain development, the response was more than additive, resulting in enhanced neurobehavioral defects. However, exposure during non-critical periods produced no effect (Eriksson et al. 2002). Deviations from normal or spontaneous behavior due to the exposure were also shown to increase with age (Eriksson et al. 2006). The behavior of an individual is an appropriate endpoint to study when evaluating potential health effects because the nervous system can be influenced by a contaminant, thereby causing a change in behavior (Eriksson et al. 2006). SRKW calves have relatively high levels of both $\Sigma$ PBDEs and $\mathrm{EPCBs}$, thereby increasing their susceptibility to 
detrimental biological health effects resulting from biochemical interactions of multiple contaminants.

There are currently no known killer whale-specific PBDE or PCB health-effects thresholds, thereby requiring the use of surrogate species to estimate associated risks. Caution must be used when extrapolating such risks across species, as pharmacodynamic and pharmacokinetic characteristics are species-specific and can influence sensitivity in a species (Schwacke et al. 2002). While this challenge constrains a causeand-effect association between POPs and health in killer whales, the conserved nature of endocrine systems and mechanisms of POP toxicity provide an opportunity for a basic assessment of health risks. For example, Kannan et al. (2000) and Ross et al. (1996) derived a health-effects threshold concentration for PCBs in marine mammal blubber of $17000 \mathrm{ng} \mathrm{g}^{-1} \mathrm{lw}$. SRKWs substantially exceed this threshold in PCB concentration (Ross et al. 2000, Krahn et al. 2007, 2009). Additionally, SRKWs have PBDE concentrations (Krahn et al. 2007, 2009) higher than those associated with altered thyroid hormone levels in post-weaned and juvenile grey seals (Hall et al. 2003).

POPs released from the blubber circulate in the body core during gestation and lactation and can potentially cause adverse health effects in reproductive female killer whales. Additionally, POP levels in reproductive females can potentially affect calf mortality. Hall et al. (2006) estimated a $50 \%$ probability of calf mortality in bottlenose dolphins when the maternal PCB blubber burden exceeded $10000 \mathrm{ng}$ $\mathrm{g}^{-1}$. Furthermore, the probability of a calf surviving the first 6 mo dropped to almost $10 \%$ when the maternal blubber burden doubled (Hall et al. 2006). In a separate study, a concentration-response curve was estimated for PCBs in bottlenose dolphins and the median effective concentration for calf mortality occurred when the total body concentration was $33000 \mathrm{ng} \mathrm{g}^{-1} \mathrm{lw}$ (Schwacke et al. 2002). In general, future projection scenarios indicate that the $\mathrm{PCB}$ concentrations in SRKW calves and adult males will continue to exceed these health-effects thresholds. Furthermore, in most current and projected reproductive-aged female SRKWs, the predicted PCB concentrations exceeded these health effects thresholds prior to giving birth to their first calf.

Given the inherent challenges associated with obtaining meaningful measurements of POPs in freeranging killer whales, our model-based approach allows us to explore these concentrations over time and under differing scenarios. An individual-based model linked to the biological processes that cause individuals to both acquire and lose contaminants over time allows one to estimate contaminant concentrations in specific individuals using their known history (e.g. birth order, reproductive history, pod membership, birth year, and sex). While concerns about the well-studied PCBs in killer whales (Ross et al. 2000, Ross 2006, Hickie et al. 2007, Krahn et al. 2007) linger, our predicted increase in $\mathrm{PBDE}$ concentrations into the future in this population highlight an emerging and poorly documented concern.

Acknowledgements. We thank Ken Balcomb and his colleagues at the Center for Whale Research, Friday Harbor, Washington, who perform the SRKW annual surveys and who provided the life history and population data. Brendan Hickie (Trent University) provided guidance and support with the beginning modeling structure. We offer additional thanks to Peter Olesiuk (Fisheries and Oceans Canada), Peggy Krahn, Eric Ward, Brice Semmens, and Yasmin Lucero (NWFSC, NOAA Fisheries), and the graduate students and staff of the VanBlaricom lab (School of Aquatic \& Fishery Sciences [SAFS], University of Washington [UW], Seattle) for their advice during the course of this study. We thank Trevor Branch and 3 anonymous reviewers for their constructively critical comments on draft versions of the manuscript. Main funding support for our work was provided by NOAA/NMFS/NWFSC, the SAFS/UW, and the Claire L. and Evelyn S. Egtvedt Fellowship. Additional support came from the Washington Cooperative Fish and Wildlife Research Unit of the US Geological Survey, located at SAFS, UW. The use of trade names or products does not constitute endorsement by the US Government.

\section{LITERATURE CITED}

Aguilar A, Borrell A (1994) Reproductive transfer and variation of body load of organochlorine pollutants with age in fin whales (Balaenoptera physalus). Arch Environ Contam Toxicol 27:546-554

Aguilar A, Borrell A, Pastor T (1999) Biological factors affecting variability of persistent pollutant levels in cetaceans. J Cetacean Res Manage 1: 83-116

Bigg MA (1982) An assessment of killer whale (Orcinus orca) stocks off Vancouver Island, British Columbia. Rep Int Whaling Comm 32:655-666

Bignert A, Olsson M, Persson W, Jensen S, Zakrisson S, Litzén K, Eriksson U, Häggberg L, Alsberg T (1998) Temporal trends of organochlorines in northern Europe, 1967-1995. Relation to global fractionation, leakage from sediments and international measures. Environ Pollut 99: $177-198$

Borgå K, Fisk AT, Hoekstra PF, Muir DCG (2004) Biological and chemical factors of importance in the bioaccumulation and trophic transfer of persistent organochlorine contaminants in Arctic marine food webs. Environ Toxicol Chem 23:2367-2385

Borrell A, Aguilar A (2005) Mother-calf transfer of organochlorine compounds in the common dolphin (Delphinus delphis). Bull Environ Contam Toxicol 75:149-156

Breivik K, Sweetman A, Pacyna JM, Jones KC (2002) Towards a global historical emission inventory for selected PCB congeners - a mass balance approach: 1. 
Global production and consumption. Sci Total Environ 290:181-198

Calambokidis J, Jeffries S, Ross PS, Ikonomou M (1999) Temporal trends in contaminants in Puget Sound harbor seals. Final Report to US EPA and Puget Sound Water Quality Action Team, Cascadia Research, Olympia, WA

Ceccatelli R, Faass O, Schlumpf M, Lichtensteiger W (2006) Gene expression and estrogen sensitivity in rat uterus after developmental exposure to the polybrominated diphenyl ether PBDE 99 and PCB. Toxicol 220:104-116

Cockcroft VG, De Kock AC, Lord DA, Ross GJB (1989) Organochlorines in bottlenose dolphins Tursiops truncatus from the east coast of South Africa. S Afr J Mar Sci 8: 207-217

Costa DP (2002) Energetics. In: Perrin WF, Thewissen JGM, Würsig B (eds) Encyclopedia of marine mammals. Academic Press, San Diego, CA, p 387-394

Cullon DL, Yunker MB, Alleyne C, Dangerfield NJ, O'Neill S, Whiticar MJ, Ross PS (2009) Persistent organic pollutants in Chinook salmon (Oncorhynchus tshawytscha): implications for resident killer whales of British Columbia and adjacent waters. Environ Toxicol Chem 28: 148-161

Darnerud PO, Eriksen GS, Jóhannesson T, Larsen PB, Viluksela M (2001) Polybrominated diphenyl ethers: occurrence, dietary exposure, and toxicology. Environ Health Perspect 109:49-68

de Swart R, Ross PS, Vedder LJ, Timmerman HH and others (1994) Impairment of immune function in harbor seals (Phoca vitulina) feeding on fish from polluted waters. Ambio 23:155-159

> Duinker JC, Hillebrand M (1979) Mobilization of organochlorines from female lipid tissue and transplacental transfer to fetus in a harbour porpoise (Phocoena phocoena) in a contaminated area. Bull Environ Contam Toxicol 23:728-732

Eriksson P, Viberg H, Jakobsson E, Örn U, Fredriksson A (2002) A brominated flame retardant, 2, 2', 4, 4', 5-pentabromodiphenyl ether: uptake, retention, and induction of neurobehavioral alterations in mice during a critical phase of neonatal brain development. Toxicol Sci 67: 98-103

Eriksson P, Fischer C, Fredriksson A (2006) Polybrominated diphenyl ethers, a group of brominated flame retardants, can interact with polychlorinated biphenyls in enhancing developmental neurobehavioral defects. Toxicol Sci 94: 302-309

Ford JKB, Ellis GM (2006) Selective foraging by fish-eating killer whales Orcinus orca in British Columbia. Mar Ecol Prog Ser 316:185-199

Ford JKB, Ellis GM, Barrett-Lennard LG, Morton AB, Palm RS, Balcomb KC (1998) Dietary specialization in two sympatric populations of killer whales (Orcinus orca) in coastal British Columbia and adjacent waters. Can J Zool 76:1456-1471

Ford JKB, Ellis GM, Olesiuk PF (2005) Linking prey and population dynamics: Did food limitation cause recent declines of 'resident' killer whales (Orcinus orca) in British Columbia? Research Document 2005/042, Canadian Science Advisory Secretariat. www.dfo-mpo.gc.ca/ CSAS/Csas/DocREC/2005/RES2005_042_e.pdf

Ford JKB, Ellis GM, Olesiuk PF, Balcomb KC (2010) Linking killer whale survival and prey abundance: food limitation in the oceans' apex predator? Biol Lett 6:139-142

Fossi MC, Marsili L (2003) Effects of endocrine disruptors in aquatic mammals. Pure Appl Chem 75:2235-2247

Fukushima M, Kawai S (1980) Variation of organochlorine residue concentration and burden in striped dolphin (Stenella coeruleoalba) with growth. In: Fujiyama T (ed) Studies on the levels of organochlorine compounds and heavy metals in the marine organisms. University of the Ryukus, Okinawa, p 97-114

Gilmartin WG, DeLong RL, Smith AW, Sweeney JC and others (1976) Premature parturition in the California sea lion. J Wildl Dis 12:104-115

Gouin T, Harner T (2003) Modelling the environmental fate of the polybrominated diphenyl ethers. Environ Int 29: 717-724

Grant SCH, Ross PS (2002) Southern resident killer whales at risk: toxic chemicals in the British Columbia and Washington environment. Can Tech Rep Fish Aquat Sci 2412

Hall AJ, Kalantzi OI, Thomas GO (2003) Polybrominated diphenyl ethers (PBDEs) in grey seals during their first year of life-are they thyroid hormone endocrine disrupters? Environ Pollut 126:29-37

Hall AJ, McConnell BJ, Rowles TK, Aguilar A and others (2006) Individual-based model framework to assess population consequences of polychlorinated biphenyl exposure in bottlenose dolphins. Environ Health Perspect 114(Suppl 1):60-64

> Hallgren S, Sinjari T, Håkansson H, Darnerud PO (2001) Effects of polybrominated diphenyl ethers (PBDEs) and polychlorinated biphenyls (PCBs) on thyroid hormone and vitamin A levels in rats and mice. Arch Toxicol 75: 200-208

> Hanson MB, Baird RW, Ford JKB, Hempelmann-Halos J and others (2010) Species and stock identification of prey consumed by endangered southern resident killer whales in their summer range. Endang Species Res 11: 69-82

Hauser DDW, Logsdon MG, Holmes EE, VanBlaricom GR, Osborne RW (2007) Summer distribution patterns of southern resident killer whales Orcinus orca: core areas and spatial segregation of social groups. Mar Ecol Prog Ser 351:301-310

> Hickey JP, Batterman SA, Chernyak SM (2006) Trends of chlorinated organic contaminants in Great Lakes trout and walley from 1970 to 1998. Arch Environ Contam Toxicol 50:97-110

Hickie BE, Kingsley MCS, Hodson PV, Muir DCG, Béland P, Mackay D (2000) A modelling-based perspective on the past, present, and future polychlorinated biphenyl contamination of the St. Lawrence beluga whale (Delphinapterus leucas) population. Can J Fish Aquat Sci 57(Suppl 1):101-112

Hickie BE, Muir DCG, Addison RF, Hoekstra PF (2005) Development and application of bioaccumulation models to assess persistent organic pollutant temporal trends in Arctic ringed seals (Phoca hispida) populations. Sci Total Environ 351-352:413-426

Hickie BE, Ross PS, MacDonald RW, Ford JKB (2007) Killer whales (Orcinus orca) face protracted health risks associated with lifetime exposure to PCBs. Environ Sci Technol 41:6613-6619

> Hites RA (2004) Polybrominated diphenyl ethers in the environment and in people: a meta-analysis of concentrations. Environ Sci Technol 38:945-956

Holt MM, Noren DP, Veirs V, Emmons CK, Veirs S (2009) Speaking up: Killer whales (Orcinus orca) increase their 
call amplitude in response to vessel noise. J Acoust Soc Am 125:EL27-EL32

- Ikonomou MG, Rayne S, Addison RF (2002) Exponential increases of the brominated flame retardants, polybrominated diphenyl ethers, in the Canadian Arctic from 1981 to 2000. Environ Sci Technol 36:1886-1892

> Ikonomou MG, Fernandez MP, Hickman ZL (2006) Spatiotemporal and species-specific variation in PBDE levels/ patterns in British Columbia's coastal waters. Environ Pollut 140:355-363

Iwata H, Tanabe S, Sakal N, Tatsukawa R (1993) Distribution of persistent organochlorines in the oceanic air and surface seawater and the role of ocean on their global transport and fate. Environ Sci Technol 27:1080-1098

> Jones KC, de Voogt P (1999) Persistent organic pollutants (POPs): state of the science. Environ Pollut 100:209-221

> Jönsson A, Gustafsson Ö, Axelman J, Sundberg H (2003) Global accounting of PCBs in the continental shelf sediments. Environ Sci Technol 37:245-255

Kajiwara N, Kamikawa S, Amano M, Hayano A, Yamada TK, Miyazaki N, Tanabe S (2008) Polybrominated diphenyl ethers (PBDEs) and organochlorines in melonheaded whales, Peponocephala electra, mass stranded along the Japanese coasts: maternal transfer and temporal trend. Environ Pollut 156:106-114

Kannan K, Blankenship AL, Jones PD, Giesy JP (2000) Toxicity reference values for the toxic effects of polychlorinated biphenyls to aquatic mammals. Hum Ecol Risk Assess 6:181-201

Klanjscek T, Nisbet RM, Caswell H, Neubert MG (2007) A model for energetics and bioaccumulation in marine mammals with applications to the right whale. Ecol Appl $17: 2233-2250$

Kleiber M (1975) The fire of life: an introduction to animal energetics, 2nd edn. Kreiger Publishing, Huntington, NY

- Kodavanti PRS (2005) Neurotoxicity of persistent organic pollutants: possible mode(s) of action and further considerations. Dose Response 3:273-305

Krahn MM, Ford MJ, Perrin WF, Wade PR and others (2004) 2004 Status review of Southern Resident killer whales (Orcinus orca) under the Endangered Species Act. US Dept Commerce, NOAA Tech. Memo, NMFS-NWFSC62

Krahn MM, Hanson MB, Baird RW, Boyer RH and others (2007) Persistent organic pollutants and stable isotopes in biopsy samples (2004/2006) from Southern Resident killer whales. Mar Pollut Bull 54:1903-1911

Krahn MM, Hanson MB, Schorr GS, Emmons CK and others (2009) Effects of age, sex and reproductive status on persistent organic pollutant concentrations in 'Southern Resident' killer whales. Mar Pollut Bull 58:1522-1599

Lamon EC III, Carpenter SR, Stow CA (1999) Rates of decrease of polychlorinated biphenyl concentrations in five species of Lake Michigan salmonids. Can J Fish Aquat Sci 56:53-39

> Lebeuf M, Gouteux B, Measures L, Trottier S (2004) Levels and temporal trends (1988-1999) of polybrominated diphenyl ethers in beluga whales (Delphinapterus leucas) from the St. Lawrence Estuary, Canada. Environ Sci Technol 38:2971-2977

Lefkovitz LF, Cullinan VI, Crecelius EA (1997) Historical trends in the accumulation of chemicals in Puget Sound. US Dept Commerce, NOAA Tech Memo, NOS ORCA 111

Legler J, Brouwer A (2003) Are brominated flame retardants endocrine disruptors? Environ Int 29:879-885

> Lusseau D, Bain DE, Williams R, Smith JC (2009) Vessel traffic disrupts the foraging behavior of southern resident killer whales Orcinus orca. Endang Species Res 6: 211-221

Marsili L, Gaggi C, Bortolotto A, Stanzani L, Franchi A, Renzoni A, Bacci E (1995) Recalcitrant organochlorine compounds in captive bottlenose dolphins (Tursiops truncates): biomagnification or bioaccumulation. Chemosphere 31:3919-3932

Matta MB, Mearns AJ, Buchman MF (1986) Trends in DDT and PCBs in US West Coast fish and invertebrates. National Ocean Service, National Oceanic and Atmospheric Administration, US Dept Commerce, Seattle, WA

Noren DP (2011) Estimated field metabolic rates and prey requirements of resident killer whales. Mar Mamm Sci 27:60-77

Noren DP, Johnson AH, Rehder D, Larson A (2009) Close approaches by vessels elicit surface active behaviors by southern resident killer whales. Endang Species Res 8: 179-192

- O'Neill SM, West JE (2009) Marine distribution, life history traits, and the accumulation of polychlorinated biphenyls (PCBs) in Chinook salmon from Puget Sound, Washington. Trans Am Fish Soc 138:616-632

O'Neill SM, Ylitalo GM, West JE, Bolton J, Sloan CA, Krahn MM (2006) Regional patterns of persistent organic pollutants in 5 Pacific salmon species (Oncorhynchus spp) and their contributions to contaminant levels in northern and southern resident killer whales (Orcinus orca). In: Proc 2006 Southern Resident Killer Whale Symp, NOAAFisheries, Northwest Fisheries Science Center, Seattle, WA. www.wdfw.wa.gov/publications/01034/wdfw01034 .pdf

O'Shea T (1999) Environmental contaminants and marine mammals. In: Reynolds JE, Rommel SA (eds) Biology of marine mammals. Smithsonian Institution Press, Washington, DC, p 485-536

Olesiuk PF, Ellis GM, Ford JKB (2005) Life history and population dynamics of Northern Resident killer whales (Orcinus orca) in British Columbia. DFO Can Sci Advis Sec Res Doc 2005/045

Osborne R (1999) A historical ecology of Salish Sea 'Resident' killer whales (Orcinus orca): with implications for management. PhD dissertation, University of Victoria

R Development Core Team (2006) R: a language and environment for statistical computing. R Foundation for Statistical Computing, Vienna

Rayne S, Ikonomou MG, Antcliffe B (2003) Rapidly increasing polybrominated diphenyl ether concentrations in the Columbia River system from 1992 to 2000. Environ Sci Technol 37:2847-2854

Rayne S, Ikonomou MG, Ross PS, Ellis GM, Barrett-Lennard LG (2004) PBDEs, PBBs, and PCNs in three communities of free-ranging killer whales (Orcinus orca) from the northeastern Pacific Ocean. Environ Sci Technol 38: 4293-4299

> Reijnders PJH (1986) Reproductive failure in common seals feeding on fish from polluted coastal waters. Nature 324: 456-457

Ridgway S, Reddy M (1995) Residue levels of several organochlorines in Tursiops truncatus milk collected at varied stages of lactation. Mar Pollut Bull 30:609-614

Ross PS (2006) Fireproof killer whales (Orcinus orca): flameretardant chemicals and the conservation imperative in 
the charismatic icon of British Columbia, Canada. Can J Fish Aquat Sci 63:224-234

Ross PS, De Swart RL, Reijnders PJH, Loveren HV, Vos JG, Osterhaus A (1995) Contaminant-related suppression of delayed-type hypersensitivity and antibody responses in harbor seals fed herring from the Baltic Sea. Environ Health Perspect 103:162-167

- Ross PS, De Swart RL, Addison RF, Van Loveren H, Vos JG, Osterhaus ADME (1996) Contaminant-induced immunotoxicity in harbour seals: wildlife at risk? Toxicol 112: 157-169

Ross PS, Ellis GM, Ikonomou MG, Barrett-Lennard LG, Addison RF (2000) High PCB concentrations in freeranging Pacific killer whales, Orcinus orca: effects of age, sex and dietary preference. Mar Pollut Bull 40: 504-515

Salata GG, Wade TL, Sericano JL, Davis JW, Brooks JM (1995) Analysis of Gulf of Mexico bottlenose dolphins for organochlorine pesticides and PCBs. Environ Pollut 88: 167-175

Schwacke LH, Voit EO, Hansen LJ, Wells RS, Mitchum GB, Hohn AA, Fair PA (2002) Probabilistic risk assessment of reproductive effects of polychlorinated biphenyls on bottlenose dolphins (Tursiops truncates) from the southeast United States coast. Environ Toxicol Chem 21: 2752-2764

Sinkkonen S, Paasivirta J (2000) Degradation half-life times of PCDDs, PCDFs, and PCBs for environmental fate modeling. Chemosphere 40:943-949

Stow CA, Carpenter SR, Amrhein JF (1994) PCB concentration trends in Lake Michigan coho and Chinook salmon. Can J Fish Aquat Sci 51:1384-1390

Tanabe S, Tanaka H, Maruyama K, Tatsukawa R (1981) Ecology and bioaccumulation of Stenella coeruleoalba: elimination of chlorinated hydrocarbons from mother striped dolphins through parturition and lactation. In: Fujiyama T (ed) Studies on the levels of organochlorine compounds and heavy metals in marine organisms. University of Ryukyus, Okinawa, p 115-121

VanBlaricom GR, Gerber LR, Brownell RL Jr (in press).

Editorial responsibility: Peter Corkeron,

West Falmouth, Massachusetts, USA
Extinctions of marine mammals. In: Levin SA (ed) Encyclopedia of biodiversity, 2nd edn. Elsevier, Amsterdam

Ward EJ, Holmes EE, Balcomb KC (2009) Quantifying the effects of prey abundance on killer whale reproduction. J Appl Ecol 46:632-640

Weijs L, Yang RSH, Covaci A, Das K, Blust R (2010) Physiologically based pharmacokinetic (PBPK) models for lifetime exposure to PCB 153 in male and female harbor porpoises (Phocoena phocoena): model development and evaluation. Environ Sci Technol 44:7023-7030

Wells RS, Tornero V, Borrell A, Aguilar A and others (2005) Integrating life-history and reproductive success data to examine potential relationships with organochlorine compounds for bottlenose dolphins (Tursiops truncatus) in Sarasota Bay, Florida. Sci Total Environ 349:106-119

West JE, O'Neill SM (2007) Thirty years of persistent bioaccumulative toxics in Puget Sound: time trends of PCBs and PBDE flame retardants in three fish species. In: 2007 Research in the Georgia Basin and Puget Sound Conference. Puget Sound Action Team, Vancouver. wdfw.wa. gov/publications/01038/

Williams TM, Estes JA, Doak DF, Springer AM (2004) Killer appetites: assessing the role of predators in ecological communities. Ecology 85:3373-3384

> Williams R, Bain DE, Smith JC, Lusseau D (2009) Effects of vessels on behaviour patterns of individual southern resident killer whales Orcinus orca. Endang Species Res 6: 199-209

Ylitalo GM, Matkin CO, Buzitis J, Krahn MM, Jones LL, Rowles T, Stein JE (2001) Influence of life-history parameters on organochlorine concentrations in free-ranging killer whales (Orcinus orca) from Prince William Sound, AK. Sci Total Environ 281:183-203

Ylitalo GM, Stein JE, Hom TE, Johnson LJ and others (2005) The role of organochlorines in cancer-associated mortality in California sea lions (Zalophus californianus). Mar Pollut Bull 50:30-39

> Yogui GT, Sericano JL (2009) Polybrominated diphenyl ether flame retardants in the US marine environment: a review. Environ Int 35:655-666

Submitted: July 14, 2011; Accepted: February 6, 2012 Proofs received from author(s): April 27, 2012 